\title{
The selection of input and output variable for performance
}

\author{
evaluation of DEA
}

Chien-Min Huang

Tainan University of Technology, Taiwan, jimmy5857t@yahoo.com.tw

\begin{abstract}
This study constructed a model for assessing the operational efficiency. The cause-effect relations of the input and output variables in the efficiency assessment were examined with Decision Making Trial and Evaluation Laboratory(DEMATEL). Amongst the many methods for testing causality in recent years, structure equation modeling (SEM) is the commonest. Arguing that SEM is often misused in the absence of theoretical support where users revise the model with data and even develop theories afterwards, applied the Decision Making Trial and Evaluation Laboratory (DEMATEL) technique to reinforce the effect of SEM when investigating the correlations among the variables affecting the flight safety efficiency of airlines. Also, DEMATEL has been widely applied to test the variables in elearning, decision-making, knowledge management, operations research, customer behavior, and selection system. Hence, apart from categorizing and collating the correlations among the input and output variables in past studies with the Pearson correlation test, this dissertation will test the correlations among the input and output variables with DEMATEL and questionnaire expert survey.
\end{abstract}

Key words: performance evaluation, DEA, DEMATEL

\section{Introduction}

As efficiency is measured to improve organizational management, the selection of input and output items must correspond to management assessment. In general, most studies used the intermediation approach, as banks are considered as the mediator of financial services that input capital and labor to convert savings into loans and investments, with amount as the measuring unit. After reviewing the variable-related literature,Joseph et al., (2012) ${ }^{1}$ concluded eight DEA variable selection models, thus suggested that integrating financial theories with DEA that contains the opinion of more operators with practice experience will be a better solution.There is much diversity among studied with respect to the selection of input and outputs.Meryem\&Pasiouras(2010) ${ }^{2}$. Most studies referred to the input and output variables proposed in past studies and analyzed the "related factors" between input and output with Pearson correlation test to explain the correlations between input and output variables. Apart from scientific approaches, Jenkins \& Anderson (2003) ${ }^{3}$ argued that the selection of inputs and outputs should be practical and reasonable. And this research to test the causality among the input and output variables in efficiency assessment and reinforce the Pearson correlation 
test in the past with DEMATEL.

\section{Experimental}

\subsection{Decision making trail and evaluation laboratory method}

DEMATELwas developed by the Battelle Memorial Institute of Geneva during 1972-1976 in the Science and Human Affairs Program for constructing a mutually associated networkbased structure to analyzed the complex situations in the real world (Grbus\&Fontela, 1972) ${ }^{4}$.

DEMATEL can be applied to analyze the correlations of issues among departments or factors among issues, so as to find the causality among issues or factors (Ho.,Tsai.,Tzeng\&Fang,2011) ${ }^{5}$. DEMATEL designs the experience, knowledge, and opinion in a model structure. Compared with SEM, apart from reflecting the causality effect among variables with the impact-relation map (IRP), it provides indicators for comparison (Tzeng.,Chiang.,Li.,2007) ${ }^{6}$. Therefore, DEMATEL explains the importance-impact relations within the cluster and verifies the mutual impact relations among factors or clusters. This study used the semi-structured interview with the interviewer as the focus and the interview outlines as the support. Through the open interview and conversation, respondents were given greater space to express their subjective perception and interpret related experience. This study smoothly interviewed nine in-service FHC associate managers or officers of higher levels and senior consultants with president experience.

\subsection{DEMATEL empirical analysis}

As it covers a wide variety of aspects, the in-depth interview was applied to compensate for the inadequacy of the related literature and experience. In terms of this study, therefore, if these requirements are met, associate managers or officers of higher levels of financial holding companies will bethe suitable targets. This study successfully interviewed nine associate managers currently working in financial holding companies and ex-senior advisors to presidents of financial holding companies.

The DEMATEL method of this study was implemented the following steps 
Step 1: Construction of the direct-relation matrix.

\begin{tabular}{r|rrrrrrrrrrrrrrrrr}
\hline & H1 & H2 & H3 & Y1 & Y2 & Y3 & I1 & I2 & I3 & P1 & P2 & P3 & S1 & S2 & S3 \\
\hline H1 & 0 & 4 & 1.6 & 2 & 3 & 4 & 1 & 2 & 1 & 2 & 3 & 3 & 4 & 2 & 1 \\
H2 & 1 & 0 & 2 & 1 & 2 & 3 & 4 & 2 & 3 & 2 & 1 & 2 & 4 & 2 & 3 \\
H3 & 2 & 4 & 0 & 1.4 & 1.2 & 3 & 2 & 4 & 2 & 1.4 & 2 & 2 & 3 & 2 & 2 \\
Y1 & 3 & 2 & 3 & 0 & 3 & 2 & 1 & 2 & 3 & 2 & 1 & 1 & 2 & 1 & 1 \\
Y2 & 1 & 4 & 2 & 1 & 0 & 2 & 1.4 & 4 & 3 & 3 & 2 & 1.4 & 1 & 2 & 2 \\
Y3 & 4 & 3 & 1.4 & 2 & 4 & 0 & 2 & 3 & 3 & 4 & 1.2 & 2 & 2 & 4 & 3 \\
I1 & 2 & 2 & 3 & 2 & 1 & 4 & 0 & 1 & 2 & 2 & 3 & 3 & 1 & 3 & 2 \\
I2 & 3 & 4 & 4 & 1.2 & 1 & 2 & 3 & 0 & 2 & 3 & 4 & 2 & 2 & 3 & 4 \\
I3 & 4 & 4 & 2 & 2 & 2 & 4 & 4 & 3 & 0 & 1 & 2 & 1 & 3 & 1.4 & 2 \\
P1 & 2 & 3 & 4 & 1.4 & 2 & 1.8 & 1.6 & 2 & 2 & 0 & 1 & 2 & 4 & 1.2 & 3 \\
P2 & 1.2 & 2 & 2 & 3 & 2 & 4 & 4 & 3 & 1 & 3 & 0 & 2 & 2 & 2 & 2 \\
P3 & 1.3 & 3 & 4 & 2 & 1.4 & 3 & 3 & 2 & 3 & 2 & 1 & 0 & 1.4 & 1 & 1 \\
S1 & 1 & 1.8 & 1.8 & 2 & 1 & 2 & 3 & 2 & 4 & 2 & 3 & 1 & 0 & 1 & 1 \\
S2 & 2 & 1.4 & 2 & 2.6 & 2 & 4 & 3 & 3 & 1.4 & 1.6 & 2 & 2 & 1 & 0 & 0 \\
S3 & 3 & 1.8 & 4 & 4 & 2 & 3 & 3 & 3 & 4 & 2 & 4 & 3 & 2 & 1.2 & 0
\end{tabular}

Step 2: Calculation of the initial matrix

$\begin{array}{lllllllllllllll}\text { H1 } & \text { H2 } & \text { H3 } & \text { Y1 } & \text { Y2 } & \text { Y3 } & \text { I1 } & \text { I2 } & \text { I3 } & \text { P1 } & \text { P2 } & \text { P3 } & \text { S1 } & \text { S2 } & \text { S3 }\end{array}$

H1 $\quad 0.0002 .8893 .3333 .0002 .7782 .4442 .6673 .0003 .4442 .1113 .1112 .1413 .4441 .5562 .667$

H2 3.2220 .0003 .4443 .3333 .5563 .4442 .6673 .1113 .4441 .4442 .6672 .6993 .2221 .5562 .889

H3 3.6673 .5560 .0003 .7783 .6673 .5562 .7783 .1113 .7781 .3332 .6673 .5563 .2221 .1113 .000

Y1 3.0003 .1113 .3330 .0003 .7783 .7783 .1113 .4444 .0001 .2222 .1111 .5522 .7781 .1113 .222

Y2 $2.8893 .7783 .7783 .8890 .0003 .6673 .0003 .4443 .7781 .2222 .6672 .286 \quad 2.3331 .0003 .111$

Y3 2.0002 .8892 .8893 .7784 .0000 .0002 .8893 .7783 .7781 .1112 .4442 .7022 .1110 .8893 .667

I1 $\quad 2.8892 .3333 .0003 .2223 .5563 .5560 .0003 .7783 .5561 .7783 .1112 .12812 .1111 .0003 .000$

I2 $3.5563 .3333 .4443 .6673 .7783 .8893 .6670 .0003 .7782 .0003 .3333 .602 \quad 2.4441 .5562 .444$

I3 $\quad 2.6373 .2442 .4874 .0243 .0003 .8273 .2792 .96 \quad 0.0001 .3333 .1112 .447 \quad 2.6851 .2223 .379$

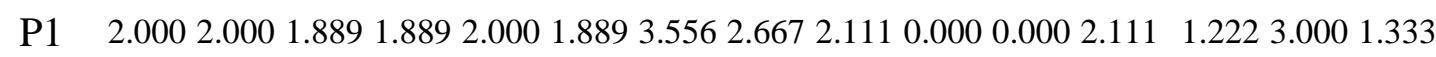

P2 3.3332 .4443 .0002 .5562 .7783 .2223 .1113 .2223 .1111 .7780 .0003 .2182 .4441 .8892 .778

P3 3.6673 .4443 .6674 .0004 .0003 .8893 .5563 .7783 .2421 .3333 .1110 .0002 .6671 .2223 .222

S1 $3.3333 .0003 .3333 .0003 .1112 .8892 .4442 .7782 .6670 .8893 .5563 .456 \quad 0.0002 .2222 .111$

$\begin{array}{llllllllllll}\text { S2 } & 2.1112 .0001 .5561 .5561 .4441 .111 & 1.556 & 1.556 & 1.444 & 1.000 & 2.0002 .126 & 2.667 & 0.000 & 0.778\end{array}$

S3 2.667 3.5563 .7783 .6674 .0003 .6673 .0003 .5563 .5563 .7783 .5563 .2963 .6673 .0000 .000 
Step 3:Establishment of the normalized direct-influence matrix.

\begin{tabular}{|c|c|c|c|c|c|c|c|c|c|c|c|c|c|c|c|}
\hline & H1 & H2 & H3 & Y1 & $\mathrm{Y} 2$ & Y3 & I1 & I2 & I3 & $\mathrm{P} 1$ & P2 & P3 & $\mathrm{S} 1$ & S2 & S3 \\
\hline H1 & 0 & 0.103 & 30.041 & 10.052 & 20.077 & 0.103 & 0.026 & 50.052 & 0.026 & 50.052 & 20.077 & 70.077 & 70.103 & 0.052 & 20.026 \\
\hline $\mathrm{H} 2$ & 0.026 & & 0.052 & 20.026 & 60.052 & 0.077 & 0.103 & 30.052 & 0.077 & 70.052 & 20.026 & 50.026 & 50.103 & 0.05 & 20.077 \\
\hline H3 & 0.052 & 0.10 & & 0.036 & 60.031 & 0.077 & 0.052 & 20.103 & 0.052 & 20.036 & 60.052 & 20.052 & 20.077 & 0.052 & 20.052 \\
\hline Y1 & 0.077 & 0.052 & 20.077 & & 0.077 & 0.052 & 0.026 & 60.052 & 0.077 & 70.052 & 20.026 & 50.026 & 60.052 & $0.02 €$ & 60.026 \\
\hline Y2 & 0.026 & 0.10 & 30.052 & 20.026 & & 0.052 & 0.036 & 60.103 & 0.077 & 70.077 & 70.052 & 20.0 & 20.026 & 0.05 & 20.052 \\
\hline Y3 & 0.103 & 0.077 & 70.036 & 50.052 & 20.103 & 0 & 0.052 & 20.077 & 70.077 & 70.103 & 30.031 & 10.031 & 10.052 & 0.103 & 30.077 \\
\hline I1 & 0.052 & 0.05 & 20.077 & 70.052 & 20.026 & 0.103 & 30 & 0.026 & 0.052 & 20.052 & 20.077 & 70.077 & 70.026 & 0.077 & 70.052 \\
\hline I2 & 0.077 & 0.103 & 30.103 & 0.031 & 10.026 & 0.052 & 0.077 & 70 & 0.052 & 20.077 & 70.103 & 30.103 & 30.052 & 0.077 & 70.103 \\
\hline I3 & 0.103 & 0.10 & 0.052 & 0.052 & 0.052 & 0.103 & 0.103 & 30.077 & 70 & 0.026 & 60.052 & 20.052 & 20.077 & 0.036 & 60.052 \\
\hline $\mathrm{P} 1$ & 0.052 & 0.077 & 70.103 & 30.036 & 60.052 & 0.046 & 0.041 & 10.052 & 20.052 & 20 & 0.026 & 50.026 & 50.103 & 0.031 & 10.077 \\
\hline P2 & 0.031 & 0.05 & 20.052 & 20.077 & 70.052 & 0.103 & 0.103 & 30.077 & 70.026 & 50.077 & 70 & 0 & 0.052 & 0.05 & 20.052 \\
\hline P3 & 0.077 & 0.052 & 20.103 & 30.103 & 30.077 & 0.026 & 0.077 & 70.052 & 0.103 & 0.052 & 20.052 & 20 & 0.052 & 0.077 & 70.036 \\
\hline S1 & 0.052 & 0.036 & 60.052 & 20.067 & 70.052 & 0.103 & 0.077 & 70.077 & 70.036 & 50.041 & 10.052 & 20.052 & 20 & $0.02 €$ & 60.052 \\
\hline S2 & 0.026 & 0.103 & 30.103 & 30.077 & 70.026 & 0.077 & 0.046 & 50.041 & 10.052 & 20.077 & 70.052 & 20.026 & 50.052 & 0 & 0.103 \\
\hline S3 & 0.077 & 0.046 & 60.103 & 30.103 & 30.052 & 0.077 & 0.077 & 70.077 & 70.103 & 30.052 & 20.103 & 30.103 & 30.052 & 0.31 & 0 \\
\hline
\end{tabular}

Step 4: Finding the total influence matrix.

\begin{tabular}{l|lllllllllllllll} 
& $\mathrm{H} 1$ & $\mathrm{H} 2$ & $\mathrm{H} 3$ & $\mathrm{Y} 1$ & $\mathrm{Y} 2$ & $\mathrm{Y} 3$ & $\mathrm{I} 1$ & $\mathrm{I} 2$ & $\mathrm{I} 3$ & $\mathrm{P} 1$ & $\mathrm{P} 2$ & $\mathrm{P} 3$ & $\mathrm{~S} 1$ & $\mathrm{~S} 2$ & $\mathrm{~S} 3$ \\
\hline $\mathrm{H} 1$ & 1.210 & 0.360 & 0.271 & 0.232 & 0.265 & 0.369 & 0.267 & 0.292 & 0.256 & 0.264 & 0.280 & 0.284 & 0.322 & 0.243 & 0.234 \\
$\mathrm{H} 2$ & 0.239 & 1.262 & 0.282 & 0.210 & 0.236 & 0.347 & 0.336 & 0.289 & 0.301 & 0.259 & 0.237 & 0.237 & 0.318 & 0.241 & 0.278 \\
$\mathrm{H} 3$ & 0.262 & 0.361 & 1.234 & 0.219 & 0.220 & 0.348 & 0.293 & 0.337 & 0.278 & 0.248 & 0.262 & 0.320 & 0.300 & 0.244 & 0.259 \\
Y1 & 0.257 & 0.284 & 0.273 & 1.156 & 0.238 & 0.287 & 0.231 & 0.260 & 0.269 & 0.231 & 0.207 & 0.207 & 0.247 & 0.192 & 0.204 \\
Y2 & 0.230 & 0.352 & 0.276 & 0.200 & 1.181 & 0.313 & 0.269 & 0.328 & 0.290 & 0.275 & 0.251 & 0.246 & 0.245 & 0.235 & 0.253 \\
Y3 & 0.350 & 0.392 & 0.316 & 0.269 & 0.325 & 1.330 & 0.335 & 0.363 & 0.343 & 0.348 & 0.283 & 0.283 & 0.321 & 0.325 & 0.321 \\
I1 & 0.250 & 0.296 & 0.289 & 0.223 & 0.207 & 0.356 & 1.224 & 0.254 & 0.260 & 0.248 & 0.266 & 0.266 & 0.237 & 0.255 & 0.243 \\
I2 & 0.324 & 0.409 & 0.375 & 0.252 & 0.251 & 0.381 & 0.361 & 1.289 & 0.318 & 0.323 & 0.347 & 0.347 & 0.321 & 0.302 & 0.343 \\
I3 & 0.337 & 0.397 & 0.312 & 0.257 & 0.266 & 0.409 & 0.367 & 0.344 & 1.258 & 0.268 & 0.289 & 0.289 & 0.329 & 0.257 & 0.284 \\
P1 & 0.251 & 0.327 & 0.319 & 0.211 & 0.229 & 0.307 & 0.271 & 0.282 & 0.270 & 1.201 & 0.229 & 0.229 & 0.314 & 0.213 & 0.270 \\
P2 & 0.251 & 0.321 & 0.292 & 0.261 & 0.246 & 0.377 & 0.340 & 0.320 & 0.260 & 0.293 & 1.216 & 1.216 & 0.279 & 0.250 & 0.264 \\
P3 & 0.251 & 0.321 & 0.292 & 0.261 & 0.246 & 0.377 & 0.340 & 0.320 & 0.260 & 0.293 & 1.216 & 1.216 & 0.279 & 0.250 & 0.264 \\
S1 & 0.210 & 0.272 & 0.244 & 0.207 & 0.188 & 0.287 & 0.252 & 1.185 & 0.245 & 0.229 & 0.252 & 0.252 & 1.194 & 0.191 & 0.203 \\
S2 & 0.252 & 0.285 & 0.269 & 0.236 & 0.230 & 0.354 & 0.269 & 0.325 & 1.234 & 0.241 & 0.247 & 0.247 & 0.236 & 1.185 & 0.245 \\
S3 & 0.334 & 0.370 & 0.379 & 0.319 & 0.282 & 0.409 & 1.330 & 0.409 & 0.375 & 0.306 & 0.351 & 0.351 & 0.324 & 0.265 & 1.250
\end{tabular}


Step 5: Drawing the net relation map (NRM) and analysis outcomes.



Based on the "total relation matrix of operational ability assessment constructs", the "influence ( $r$ )" and "received influence $(d)$ " of the constructs were obtained after summating the rows and columns to produce the"prominence" $(r+d)$ and "relation" $(r-d)$. "Influence $(r)$ " is the total strength of influence of a factor on the other factors and"receivedinfluence $(d)$ " is the total strength of influence received by a factor from other factors. "Prominence $(r+d)$ " represents the total strength of influence among the factors. The total strength of influence and influence received among the factors show the influence relationships of factors in the entire structure. If $(r+d)>0$ and the value is greater, the centrality of factors is greater. This is to say that it has a greater importance and stronger relations among all the assessment factors. "Relation $(r-d)$ " refers to the causality among factors, that is, the influence or received influence. The strength of causality reflects thecorrelation of a factor with other factors. If $(r$ $d)>0$ and the value is greater, this factor has a greater influence on other factors. If $(r-d)<0$ and the value is smaller, this factor receives a greater influence from the other factors.The total "total impact relations" of operational ability assessment constructs are shown in Table 1. As shown in the table, "revenue ability" $\left(D_{1}\right)$ has the highest prominence (8.330), "profitability" $\left(D_{2}\right)$ the second highest (7.701), and operational ability $\left(D_{3}\right)$ the least (6.292). This suggests that "revenueability"is the most influential and the most important construct in the entire structure; while "operational ability" is the least influential.

In terms of causality, "sales ability" and "operational ability" are the two of the five professional abilities with positive values; with an inclination toward the "initial relation category", which belongs to the active influence factors. The relationship value of "operational ability" is the greatest and most positive (0.421), suggesting that "operational 
ability" has a greater direct influence on other ability constructs than vice versa. As its prominence is the smallest, it has a weaker total impact relationship.

The "relation" value of "revenue ability" and "profitability" is negative, with an inclination toward the "effect relation category", which belongs to the passive influence factors. This suggests that other constructs influence these two factors more than they can influence others. "Profitability" has the lowest "relation" value (-0.142), that is, it is a factor of low relationship butwith a high prominence, with an inclination toward effect, representing that it is most easily influenced by other constructs. This result suggests that "profitability" is the most critical and most important core ability for enhancing operating efficiency, but it is most easily influenced by other active influence factors.

Table 1 - Total Impact Relationship of Operating ability assessment constructs

\begin{tabular}{|l|c|c|c|c|c|}
\hline & $\begin{array}{l}\text { received } \\
\text { influence }(d)\end{array}$ & $\begin{array}{l}\text { influence } \\
(r)\end{array}$ & $\begin{array}{l}\text { prominence } \\
(r+d)\end{array}$ & $\begin{array}{l}\text { Relation } \\
(r-d)\end{array}$ & priority \\
\hline sales ability & 3.811 & 3.751 & 7.562 & 0.060 & 3 \\
\hline revenue ability & 3.850 & 4.479 & 8.330 & -0.629 & 1 \\
\hline profitability & 3.780 & 3.922 & 7.701 & -0.142 & 2 \\
\hline $\begin{array}{l}\text { operational } \\
\text { ability }\end{array}$ & 3.357 & 2.936 & 6.292 & 0.421 & 4 \\
\hline
\end{tabular}

\section{Conclusions}

Concluding the above, the operating efficiency of the input-output ability assessment model of financial holding companies constructed by this study verified the operating ability construct and the input-output criteria of financial companies. By further analyzing the impact relationship and inter-relationship among individual operating ability constructs and inputoutput criteria with DEMATEL, the constructs and criteria that are the most critical core abilities and the most important operating abilities of financial holding companies are located. From the causality among constructsand criteria, we can better understand the mutual influence among the ability constructs and criteria. When assessing operational efficiency, these results provide a reference for prioritizing the improvement of operating abilities to enhance operating efficiency.

Overall, the operating efficiency in this study was developed based on the literature investigating the operating efficiency, the input-output variables in the related literature and the titles were used as the sources of variables. Expert interviews and thecausality survey were implemented in accordance with the steps in DEMATEL. The outcomes of the test for causality among the input-output variables show a high impact relationship among the variables. The four constructs of this study included: “operational ability”, "sales ability”, 
"profitability” and "revenue ability". The criteria in each construct included: "employees”, “operating expenses”, “capital”, “total assets”, “total liabilities” and “interest expenses” in "sales ability"; “interest income”, "non-interest income” and "income on investments" in "revenue ability"; "operating income”, "net profits before taxes”, and "net worth" in "profitability"; and "ROA", "ROE", and "EPS" in "revenue ability". These operating constructs and input-output items are the references of thevariables in the multi-stage DEA of performance evaluation of this study.

\section{References}

1. Joseph C., Paradi.,HaiyanZhu.A survey on bank branch efficiency and performance research with data envelopment analysis. Omerga 21,(2012)133 142.

2. MeryemDuygunFethi. \&FotiosPasiouras. Assessing bank efficiency and performance with operational research and artifical intelligence techniques: A survey. European Journal of Operational Research 204,(2010)190-191

3. Jenkins L. \& Anderson M.A multivariate statistical approach to reducing the number of variables in data envelopment analysis. European Journal of Operational Research 147(1), (2003)51-61.

4. Grbus A. \&Fontela E.World problems an invitation to further thought within the framework of DEMATEL. SwitzerlandGeneva:BattleGeneva Research Centre.(1972)101-223

5. HoJ.W.,Tsai C.L.,Tzeng G.H \& Fang S.KCombined DEMATEL technique with a novel MCDM model for exploring portfolio selection based on CAPM. Expert systems with applications38(1),(2011)16-25

6. TzengG.H.,Chiang C.H. \& $\mathrm{Li}$ C.W.Evaluating intertwined effects in E-learning programs:A novel hybrid MCDM modelbased on factor analysis and DEMATEL.Expert Systems with Application 32(4),(2007)1028-1044.Book citation: 